\title{
Surface-based characteristics of the cerebellar cortex visualized with ultra-high field MRI
}

\author{
Yohan Boillat $^{\mathrm{a}, \text {, }}$, Pierre-Louis Bazin ${ }^{\mathrm{b}, \mathrm{c}}$, Kieran O'Brien ${ }^{\mathrm{d}, \mathrm{k}}$, Mário João Fartaria ${ }^{\mathrm{e}, \mathrm{f}}$, \\ Guillaume Bonnier $^{\mathrm{j}}$, Gunnar Krueger ${ }^{\mathrm{g}}$, Wietske van der Zwaag ${ }^{\mathrm{h}, \mathrm{i}, 1}$, Cristina Granziera ${ }^{\mathrm{j}, 1,1}$ \\ ${ }^{a}$ Laboratory for Functional and Metabolic Imaging, Ecole Polytechnique Fédérale de Lausanne, Lausanne, Switzerland \\ ${ }^{\mathrm{b}}$ Department of Neurophysics, Max Planck Institute for Human Cognitive and Brain Sciences, Leipzig, Germany \\ ${ }^{\mathrm{c}}$ Department of Neurology, Max Planck Institute for Human Cognitive and Brain Sciences, Leipzig, Germany \\ ${ }^{\mathrm{d}}$ Siemens Healthcare Pty Ltd., Bowen Hills, Australia \\ ${ }^{\mathrm{e}}$ Department of Radiology, Centre Hospitalier Universitaire Vaudois (CHUV) and University of Lausanne (UNIL), Lausanne, Switzerland \\ ${ }^{\mathrm{f}}$ Advanced Clinical Imaging Technology (ACIT, HC CEMEA SUI DI BM PI), Siemens Healthcare AG, Lausanne, Switzerland \\ ${ }^{\mathrm{g}}$ Siemens Medical Solutions USA IM MR COL NEZ, Burlington, MA, USA \\ ${ }^{\mathrm{h}}$ Biomedical Imaging Research Center, Ecole Polytechnique Fédérale de Lausanne, Lausanne, Switzerland \\ ${ }^{\mathrm{i}}$ Spinoza Centre for Neuroimaging, Amsterdam, Switzerland \\ ${ }^{\mathrm{j}}$ A.A. Martinos Center for Biomedical Imaging, Massachusetts General Hospital and Harvard Medical School, Charlestown, MA, USA \\ ${ }^{\mathrm{k}}$ Centre for Advanced Imaging, University of Queensland, Australia \\ ${ }^{1}$ Neurology, Department of Clinical Neurosciences, CHUV and University of Lausanne, Netherlands
}

\section{A R T I C L E I N F O}

\section{Keywords:}

Cerebellum

Ultra-high field

$\mathrm{T}_{1}$

$\mathrm{T}_{2}$ *

Surface

Tissue content

\begin{abstract}
A B S T R A C T
Although having a relatively homogeneous cytoarchitectonic organization, the cerebellar cortex is a heterogeneous region characterized by different amounts of myelin, iron and protein expression profiles. In this study, we used quantitative $\mathrm{T}_{1}$ and $\mathrm{T}_{2}{ }^{*}$ mapping at ultra-high field (7T) MRI to investigate the tissue characteristics of the cerebellar gray matter surface and its layers. Detailed subject-specific surfaces were generated at three different cortical depths and averaged across subjects to create averaged $\mathrm{T}_{1}$ - and $\mathrm{T}_{2}{ }^{*}$-maps on the cerebellar surface. $\mathrm{T}_{1}$ surfaces showed an alternation of lower and higher $\mathrm{T}_{1}$ values when going from the median to the lateral part of the cerebellar hemispheres. In addition, longer $\mathrm{T}_{1}$ values were observed in the more superficial gray matter layers. $\mathrm{T}_{2}{ }^{*}$-maps showed a similar longitudinal pattern, but no change related to the cortical depths. These patterns are possibly due to variations in the level of myelination, iron and zebrin protein expression.
\end{abstract}

\section{Introduction}

The cerebellar cortex is characterized by a relatively homogenous structure - in contrast to the cytoarchitectonic heterogeneity of the neocortex - which consists of three cellular layers named granular, Purkinje and molecular layer (Cajal, 1911). Nevertheless, a number of animal studies showed that the cerebellar cortex is parcelled into distinct "zones" (Apps and Hawkes, 2009; Cerminara et al., 2015; Voogd, 2011). Longitudinal zones were observed based on the spatial distribution of cerebellar connectivity (i.e. climbing and mossy fibers; Groenewegen and Voogd, 1977; Pijpers et al., 2005, 2006; Ruigrok, 2011; Sugihara, 2004; Fujita et al., 2010; Fujita and Sugihara, 2013) and parasagittal stripes were distinguished based on protein expression patterns, i.e. zebrin II, in a subset of Purkinje cells (PCs; Brochu et al., 1990; Marzban and Hawkes, 2011). Parasagittal stripes and longitudinal zones represents functional units with distinct synchronous neuronal spiking activities which may, for instance, play a role in the parallel processing of sensory information (Apps and Hawkes, 2009; Tsutsumi et al., 2015; Witter and De Zeeuw, 2015). Moreover, non-longitudinal variations have been observed in the cerebellar cortex, due to variations in myelination at different cortical depths (Wyatt et al., 2005) as well as cell densities, sizes and distribution across lobes, phylogenetic areas or cortex concavities (Armstrong \& Schild, 1970; Lange, 1982; Müller and Heinsen, 1983).

The above studies have been performed in animals using microscale techniques such as electrophysiology and immunochemistry. Whether microscale structural patterns can be seen at the submillimeter range in

\footnotetext{
* Corresponding author. Laboratory for Functional and Metabolic Imaging, LIFMET-CIBM, Station 6, École Polytechnique Fédérale de Lausanne, CH-1015 Lausanne, Switzerland.

E-mail address: yohan.boillat@epfl.ch (Y. Boillat).

1 Equally contributed.
} 
the human cerebellar cortex is still unknown.

In recent years, software and hardware developments in ultra-high field magnetic resonance imaging (UHF MRI) have provided images with adequate spatial resolution as well as sufficient contrast- and signalto-noise ratios to perform quantitative investigations of the human cerebral cortex at a laminar level (Dinse et al., 2015; Duyn, 2012; van der Zwaag et al., 2015). Thanks to these developments, our group also achieved the visualization of the granular and molecular layers in the cerebellum in humans in vivo (Marques et al., 2010b). Studies on the cerebral cortex showed that, combining the advantages of UHF MRI with quantitative MR acquisitions, it is possible to obverse macroscopic patterns of quantitative MR contrasts on the cortical surface and within its layers, which derive from the underlying tissue composition. Quantitative $\mathrm{T}_{1}$ $\left(\mathrm{qT}_{1}\right)$ and $\mathrm{T}_{2} *\left(\mathrm{qT}_{2}{ }^{*}\right)$ maps at $7 \mathrm{~T}$ reflect the distribution in myelin and/or iron concentrations (Bonnier et al., 2014; Cohen-Adad, 2014; Helms, 2013; Hwang et al., 2010), as confirmed by histology studies (Fukunaga et al., 2010; Stüber et al., 2014). These contrasts have been used to map changes in healthy subjects (Cohen-Adad et al., 2012; Dinse et al., 2015; Sereno et al., 2013) and in multiple sclerosis (MS) patients (Bonnier et al., 2015, 2014; Mainero et al., 2015). Quantitative $\mathrm{T}_{1}$ - and $\mathrm{T}_{2}{ }^{*}$-maps of the cerebellar cortical surface may help to understand the physiopathology of a number neurological and psychiatric diseases affecting the cerebellar cortex (i.e. MS (Fartaria et al., 2016; Kutzelnigg et al., 2007), cerebellar ataxia (Schniepp et al., 2017), cortico-basal degeneration (Piao et al., 2002), progressive supranuclear palsy (Piao et al., 2002), post-traumatic stress disorder (Meabon et al., 2016)).

To date, however, microstructural studies of the cerebellar cortex in humans in vivo are lacking, mainly due to the small size of the cerebellar cortex and its convoluted structure. In this work, we performed a surfacebased investigation of microstructural properties of cerebellar human cortex in vivo by leveraging the high-spatial resolution and the $\mathrm{qT}_{1}$ and $\mathrm{qT}_{2}{ }^{*}$ contrasts at ultra-high field MRI.

\section{Methods}

\section{Participants}

Nine healthy participants ( 2 females, age $=21-43$, right-handed) were enrolled in this experiment. All participants provided written informed consent and the studies were approved by the local ethics committee. All participants had no history of neurological, psychiatric or systemic diseases. These participants were the healthy controls of a larger study involving multiple sclerosis patients (Boillat et al., 2016).

\section{Acquisition}

Data were acquired on a head-only 7T scanner (Siemens, Germany) using a 32 channel head coil (Nova Medical USA). A whole-brain $\mathrm{T}_{1}$ image was acquired using the MP2RAGE sequence (Marques et al., 2010a; repetition time $\mathrm{TR}=6000 \mathrm{~ms}$, echo time $\mathrm{TE}=2.84 \mathrm{~ms}$, first inversion time $\mathrm{TI}_{1}=750 \mathrm{~ms}$, second inversion time $\mathrm{TI}_{2}=2350 \mathrm{~ms}$, first flip angle $=4^{\circ}$, second flip angle $=5^{\circ}$, matrix size $300 \times 320 \times 160$, voxel size $0.75 \times 0.75 \times 0.9 \mathrm{~mm}^{3}$ ). MP2RAGE is a sequence combining two images generated at different inversion times $\left(\mathrm{INV}_{1}\right.$ and $\mathrm{INV}_{2}$ sampled at $\mathrm{TI}_{1}$ and $\mathrm{TI}_{2}$, respectively) to create a synthetic $\mathrm{T}_{1}$-weighted image free of $\mathrm{T}_{2}{ }^{*}$ and proton density contrast, reception bias field and transmit field inhomogeneity (first order). A map of the transmit $B_{1}$ field was acquired with a SA2RAGE sequence (Eggenschwiler et al., 2012; $\mathrm{TR}=2400 \mathrm{~ms}, \quad \mathrm{TE}=0.72 \mathrm{~ms}$, matrix $116 \times 128 \times 64$, voxel size $2.3 \times 2.3 \times 4 \mathrm{~mm}^{3}$, same transmit voltage as MP2RAGE). The $\mathrm{T}_{2}^{*}$-maps were generated from a 3D multi gradient echo, MGE, dataset with nine echo times $(\mathrm{TR}=45 \mathrm{~ms}$, TE1 $=4.59 \mathrm{~ms}$, TE $9=41.3 \mathrm{~ms}$, with an echo spacing, $\Delta \mathrm{TE}$, of $4.59 \mathrm{~ms}$, matrix size $300 \times 320 \times 160$, voxel size $0.75 \times 0.75 \times 0.9 \mathrm{~mm}^{3}$ ). Three dielectric pads were placed around the upper neck to improve the inversion efficiency over the cerebellum and whole brain $B_{1}$ homogeneity (Teeuwisse et al., 2012).

\section{Data processing}

For every dataset, a mono-exponential fit to the MGE data was used to obtain the $\mathrm{S}_{0}$ (signal at $\mathrm{t}=0$ ) and $\mathrm{T}_{2}{ }^{*}$-maps (Van der Weerd et al., 2000). $\mathrm{S}_{0}$ was registered with a rigid body transformation to the $\mathrm{INV}_{2}$ image from the MP2RAGE using Elastix (Klein et al., 2010) and the obtained transformation was subsequently applied to the $\mathrm{T}_{2}{ }^{*}$-map. The parameters of this MP2RAGE protocol were carefully chosen to limit $\mathrm{B}_{1}$-sensitivity over the range of $B_{1}$-values expected in the cerebellum (Fig. S1). In addition, the MP2RAGE $T_{1}$-maps were corrected for residual $B_{1}$-inhomogeneities using the SA2RAGE $\mathrm{B}_{1}$-map, following the procedure

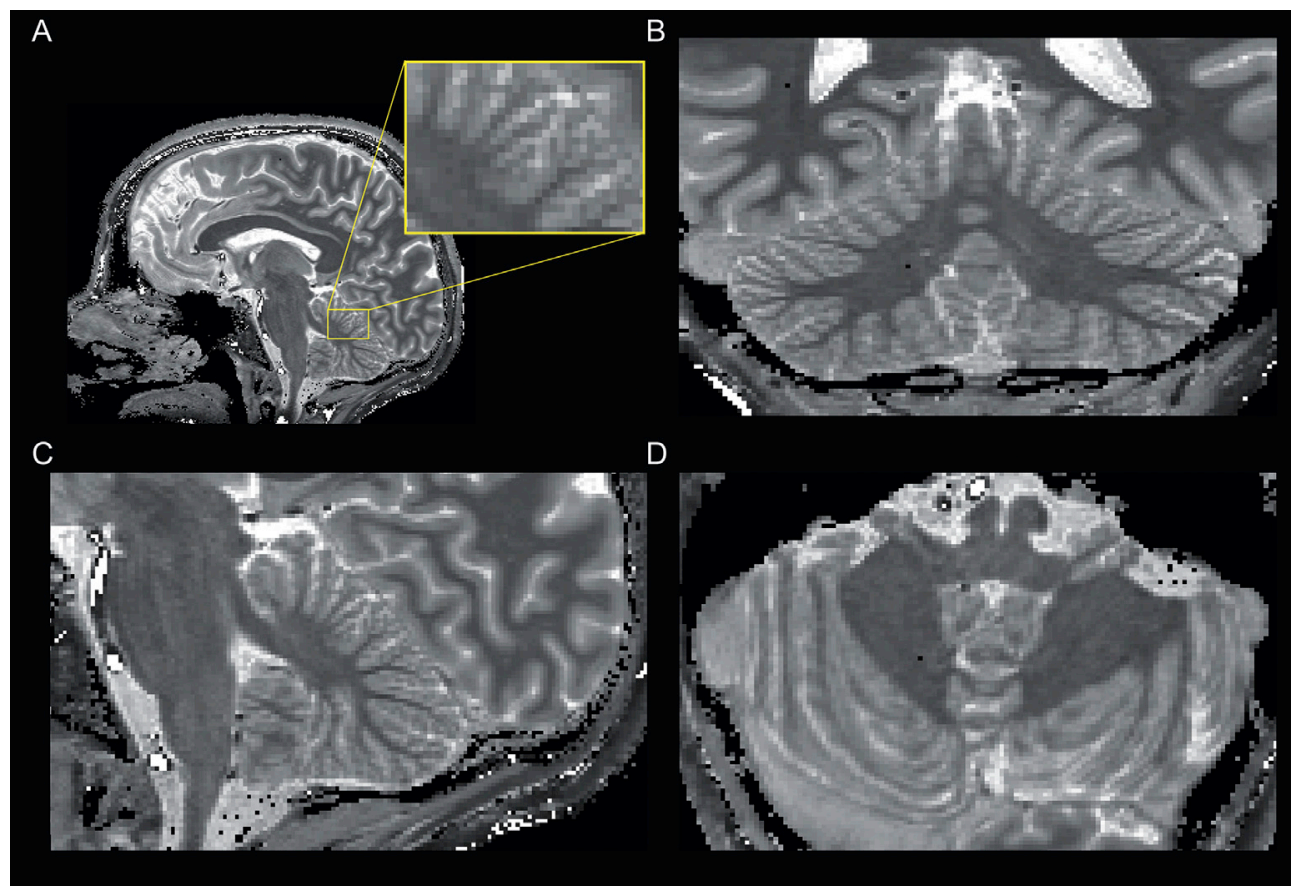

Fig. 1. Example of a raw $\mathrm{T}_{1}$-map (voxel size of $0.75 \times 0.75 \times 0.9 \mathrm{~mm}^{3}$ ). A) A whole brain sagittal slice with a zoomed-in region on the folia (yellow square). B) Coronal, C) sagittal and D) axial slices through the cerebellum. 

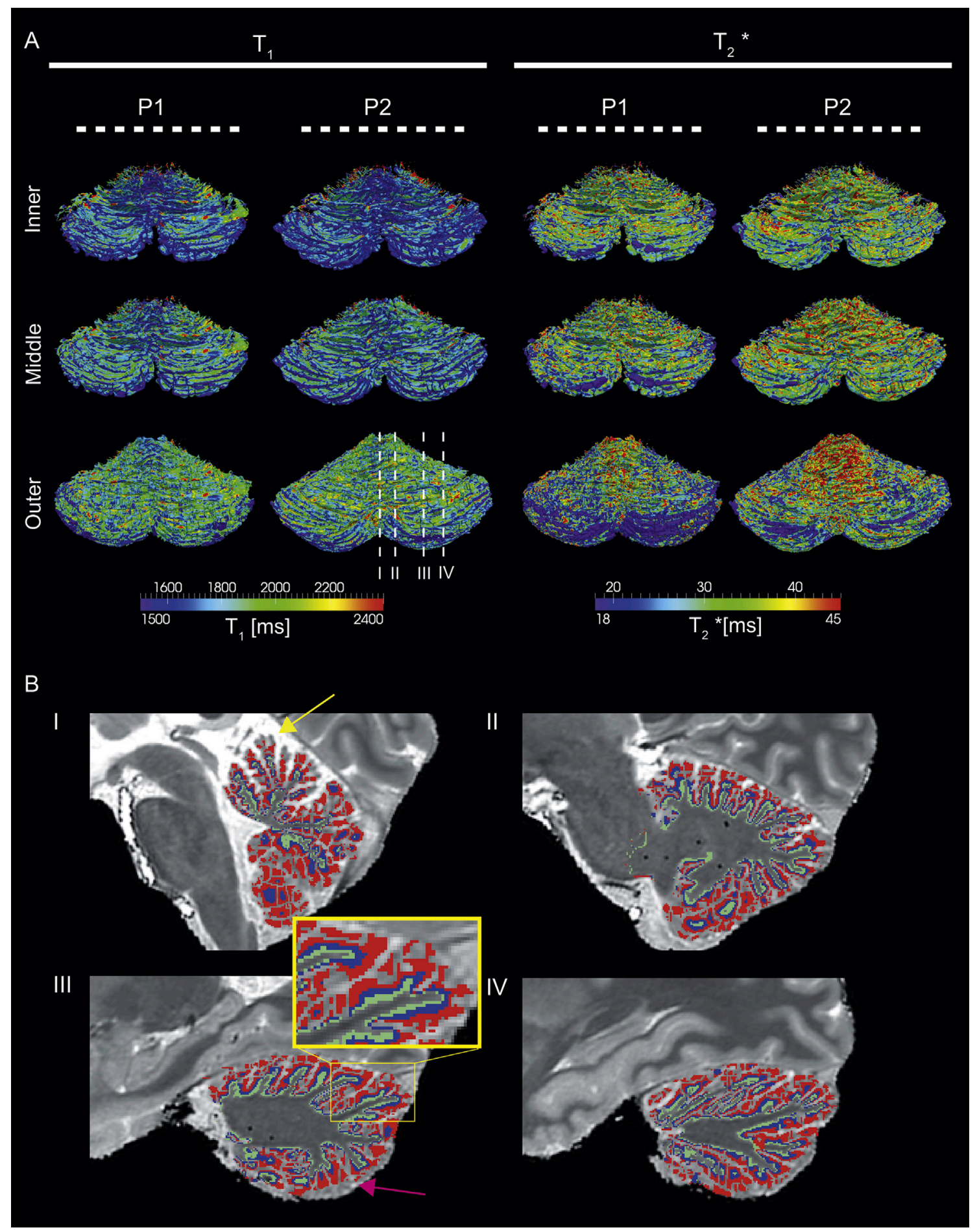

Fig. 2. A) Single-subject surfaces of two participants ( $P 1$ and $P 2$ ) mapped with $T_{1}$ and $T_{2}{ }^{*}$ values. B) Sagittal cuts of $P 2$ at four different positions from the medial to the more lateral part of the right hemisphere, indicated with a white dotted line on the outer $\mathrm{T}_{1}$ surface. The segmentation results are shown overlaid on the $\mathrm{T}_{1}$ map for the inner (green), middle (blue) and outer (red) cortical depths. The yellow arrow indicates an underestimated part of the cerebellar cortex at the level of the vermis of the anterior lobe. The purple arrow indicates a similar region in the bottom part of the posterior lobe. No additional smoothing was applied to these surfaces.

described in Marques and Gruetter (2013). For the subsequent analysis steps the CBS tools toolbox (Bazin et al., 2013) was used. All images were skull-stripped using SPECTRE (Carass et al., 2011). The $\mathrm{T}_{1}$-weighted image was brought into the MNI space using a global linear registration algorithm based on FLIRT (Jenkinson and Smith, 2001) and the resulting transformation map was applied to the $\mathrm{T}_{1^{-}}$and $\mathrm{T}_{2}{ }^{*}$-maps. The segmentation was performed with the $\mathrm{T}_{1}$ image (thresholded at $4000 \mathrm{~ms}$ ) as input along with filters for dura matter, CSF and arteries (see Bazin et al., 2014), using the multi-geometric deformable model segmentation algorithm (MGDM; Bogovic et al., 2013). The MGDM algorithm segmented the brain in 30 different structures, including the cerebellum white (WM) and (GM) matter regions. The merging of WM and GM resulted in a cerebellar mask which was manually corrected to remove extra-cerebellar tissues (such as remaining small parts of the occipital 


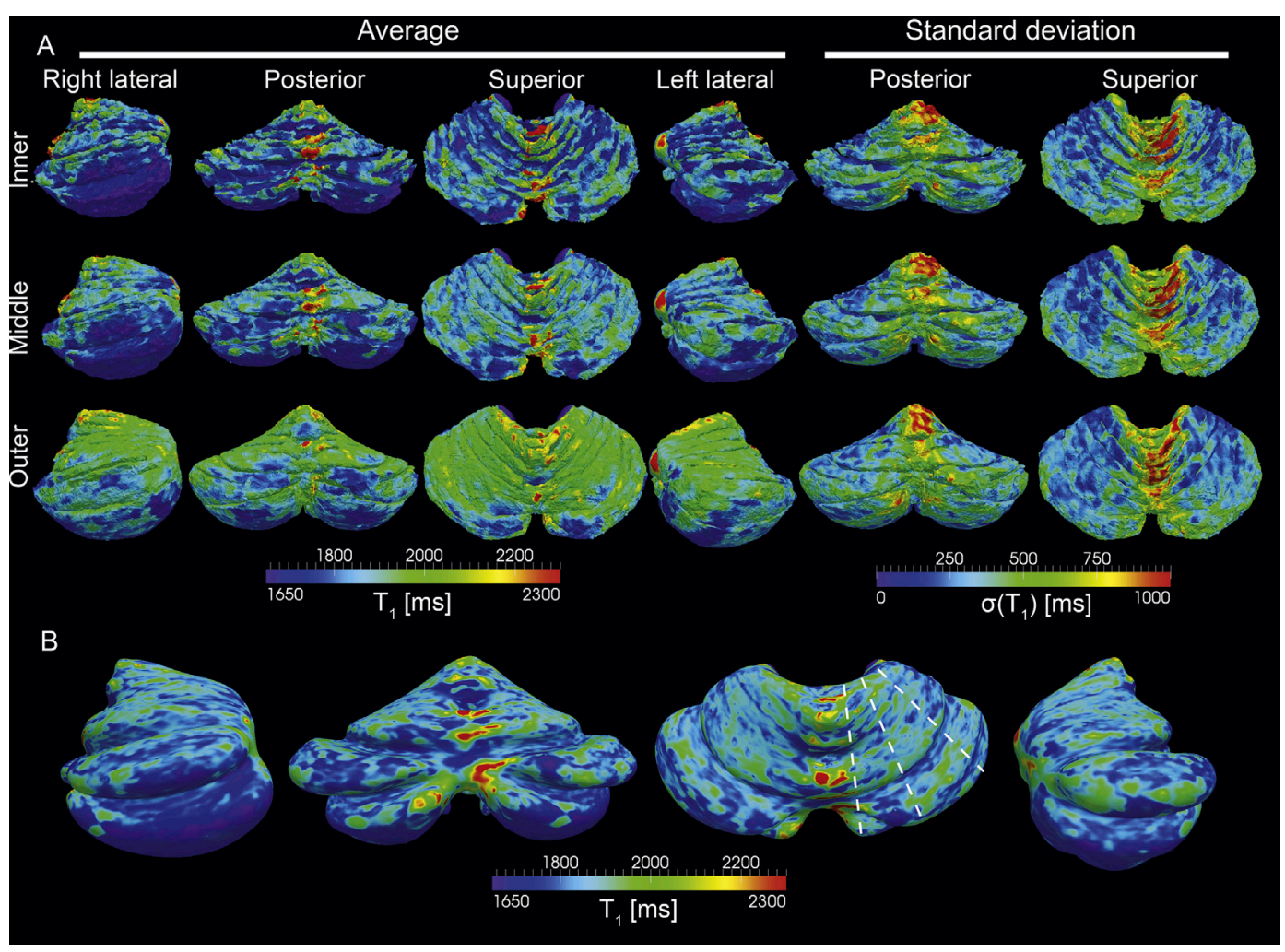

Fig. 3. $\mathrm{T}_{1}$ mapping on the cerebellar surfaces. A) Mapping of the mean (left) and standard deviation (right) of $\mathrm{T}_{1}$ values at the three cortical depths on their respective averaged folded surfaces brought into the CHROMA space. B) $T_{1}$ values mapped on the inflated surface of the CHROMA atlas $\mathrm{T}_{1}$-map at the middle cortical depth. The white dashed lines indicate the borders of zones with lower and higher $\mathrm{T}_{1}$ values. A Gaussian function of $2 \mathrm{~mm}$ FWHM was applied for smoothing.

cortex or brainstem) with ITK-SNAP (Yushkevich et al., 2006). The masked $\mathrm{T}_{1}$-maps were then segmented using FANTASM (Pham, 2001) which provided a fine delineation of GM, WM and cerebrospinal fluid (CSF) borders. The WM-GM border and GM-CSF border level sets were extracted with an adaptation of the CRUISE algorithm (Han et al., 2004), a topology-preserving technique, ensuring spherical topology (Euler number of 2). Using the level sets, a continuous layering of the cerebellar cortex was built at three different cortical depths following a volume-preserving model of cortical folding where the volume fraction of a segment taken across the GM is constant across the whole cortical depth: the curvature is compensated by a change of the thickness of the cortical depth (Waehnert et al., 2014). On average, each layer represents one third of the total cortical thickness. While the complexity of the cerebellar folia cannot fully be captured at this spatial resolution each layer provides a different bias towards the deep, middle or superficial layers of the cerebellar cortex (inner, middle and outer layer, respectively). A diffeomorphic image registration algorithm (ANTs; Avants et al., 2008) was used to realign the $T_{1}$-maps to a high-resolution template (CHROMA atlas, a group-wise average of a $\mathrm{T}_{1}$-map acquired at $0.7 \mathrm{~mm}$ isotropic resolution) from the CBS Tools. The transformation map obtained from the previous procedure was applied to the inner, middle and outer surfaces to realign them. The aligned level set representations of the surfaces are then averaged across subjects for each separate surface, and the final group average surface is extracted as their zero-level set. Averaged $\mathrm{T}_{1}$ and $\mathrm{T}_{2}{ }^{*}$ values were then mapped onto the inner, middle and outer averaged surfaces as well as their standard deviation. Inflated surfaces generated from the CHROMA atlas $\mathrm{T}_{1}$-map were overlaid with the mean $T_{1}$ and $T_{2}$ * values from this group of subjects. For a better visualization, averaged surface values were smoothed along the cortex with a Gaussian function of $2 \mathrm{~mm}$ FWHM.
A

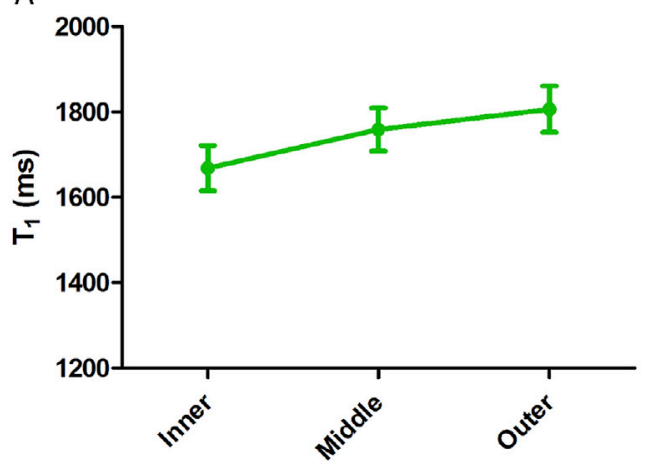

B

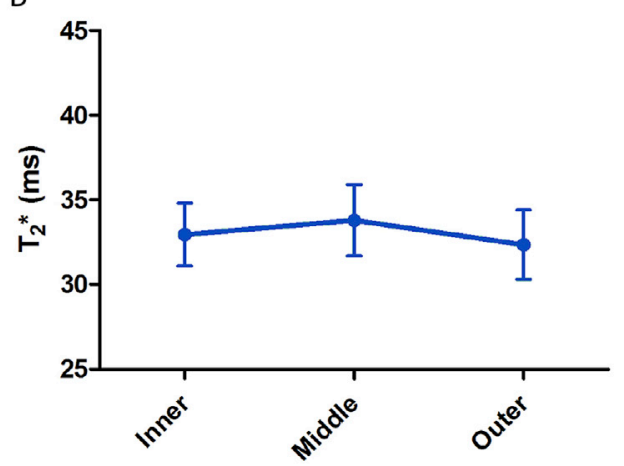

Fig. 4. Average $T_{1}(A)$ and $T_{2}{ }^{*}(B)$ values of the inner, middle and outer cortical depths. Values were averaged across spatial location and subjects. The error bars represent the standard deviation of the subject means. 


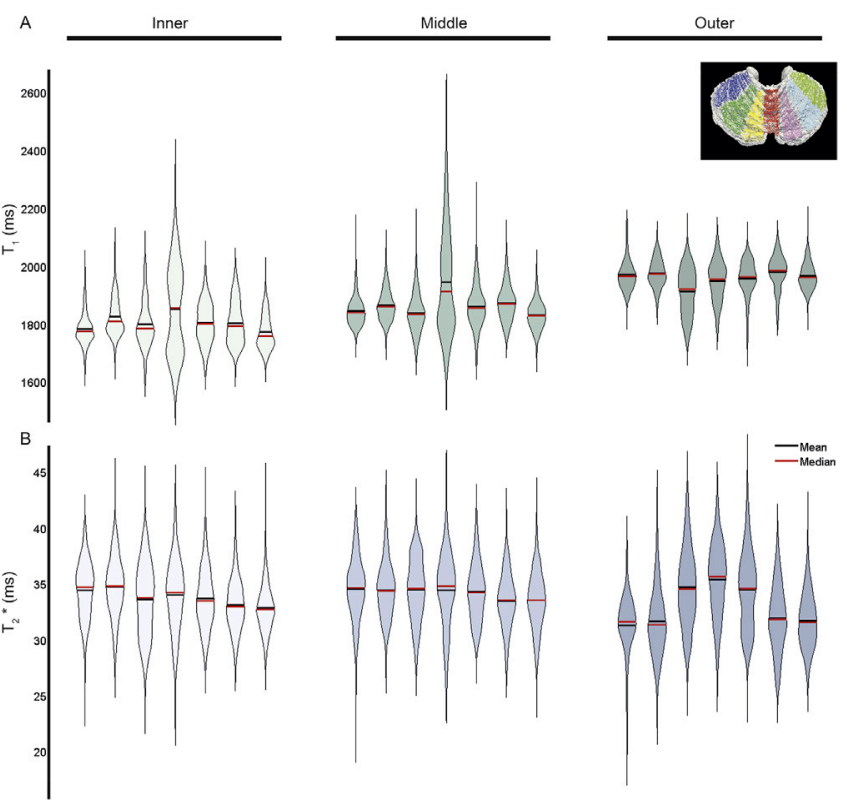

Fig. 5. Violin plots representing $A) T_{1}$ and $\left.B\right) T_{2} *$ values extracted from seven different parasagittal regions of the anterior lobe (including lobule VI) of the averaged cerebellar surfaces for the three cortical depths. The seven regions are the ones indicated by different colours on the small cerebellar surface in the top right corner.

\section{Results}

\section{Layer segmentation and single-subject surfaces}

The main parts of the arbor vitae and folia of the cerebellum were distinguishable at the present resolution (Fig. 1), however the finer branching inside a single folium were difficult to distinguish due to partial volume effects (see Fig. S2 in the supplementary material for more examples of single subject $\mathrm{T}_{1}$ ). The cerebellar gray matter of all participants could be segmented into inner, middle and outer cortical depths. Although a clear delineation of the different lobules and the general shape of the arbor vitae was achieved, many individual folia were not completely resolved. Hence, these cortical depths refer predominantly, but not exclusively, to the expected tissue types in the cerebellar cortex (Fig. 2B). However, some parts such as the anterior vermis and the bottom region of the posterior lobe were underestimated (yellow and purple arrow in Fig. 2, respectively). The surfaces of each single participant showed a consistent preservation of the anatomy, in which the different lobules could be observed (Fig. 2A). Single-subject mapping of $\mathrm{T}_{1}$ and $\mathrm{T}_{2}$ * revealed consistent patterns as can be judged from the surfaces of $\mathrm{P} 1$ and P2 shown in Fig. 2.

\section{$T_{1}$ mapping}

Qualitative analysis of the $\mathrm{T}_{1}$-maps near the vermis showed highest values for each of the three cortical depths (Fig. 3A), while the lowest values were observed on the posterior lobe. On average, the $T_{1}$ values increased by $8.3 \%$ going from the inner to the outer cortical depths (Fig. $4 \mathrm{~A})$. The hemispheres showed low $\mathrm{T}_{1}$ values that increased when going more laterally to decrease again in the very lateral regions. This pattern is mainly observed on the inner and middle surfaces and remains visible on the inflated surfaces (Fig. 3B with the dashed lines indicating the borders between stripes of higher and lower $\mathrm{T}_{1}$ values). These observations are consistent with values extracted from the anterior lobe (Fig. 5A), where the plots depicting the inner, middle and outer surfaces show alternating mean $\mathrm{T}_{1}$ values. The seven sagittal stripes of the violin plots were chosen based on a data-driven approach as the actual spatial frequency of these parasagittal stripes in humans is currently not known. Globally, $\mathrm{T}_{1}$ values were lower in the posterior lobe. The inter-subject variability was higher in the vermis than in the cerebellar hemispheres. The latter was reduced in the cerebellar hemispheres, especially in the lateral regions. Confirming the high quality of the segmentation, no systematic pattern was observed between the apex of the lobules.

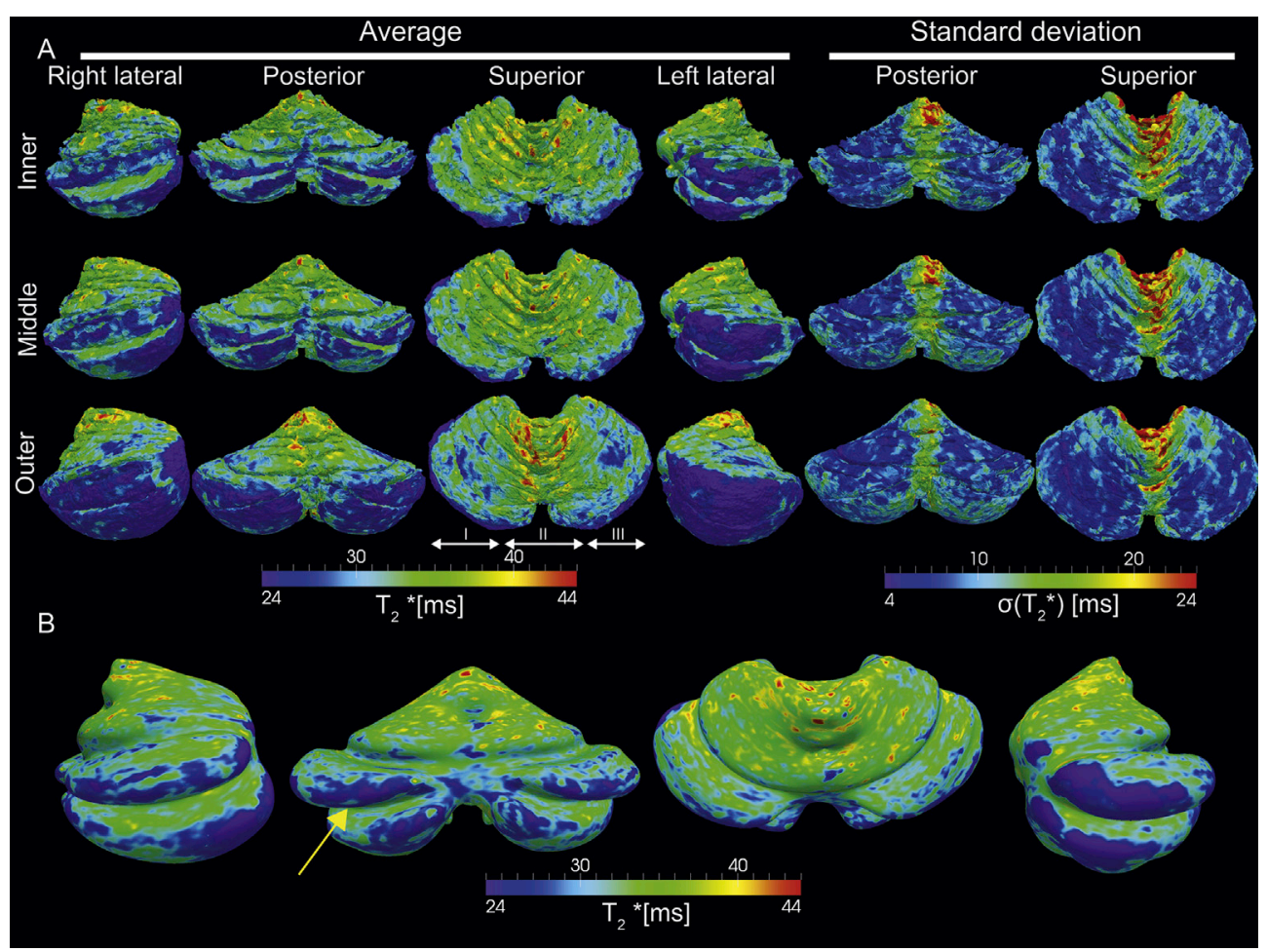

Fig. 6. Cerebellar surfaces mapped with $\mathrm{T}_{2}$ * values. A) The averaged $T_{2}$ * values (left) with their standard deviation (right) mapped on averaged folded surfaces of the nine participants brought in the CHROMA space with the inner, middle and outer surfaces. The white arrows indicate the change of longitudinal patterns alternating between lower (I and III) and higher (II) $\mathrm{T}_{2}{ }^{*}$ values. B) Averaged $T_{2}{ }^{*}$ values mapped on the middle inflated surface created from the CHROMA atlas $\mathrm{T}_{1}$-map. The yellow arrow indicated the "concavity-related" pattern on the folia's apex. A Gaussian function of $2 \mathrm{~mm}$ FWHM was applied for smoothing. View from left to right of the averaged surfaces: right lateral, posterior, superior and left lateral. 


\section{$T_{2} *$ mapping}

$\mathrm{T}_{2}$ * values showed a different pattern than the $\mathrm{T}_{1}$ values. Mean $\mathrm{T}_{2}$ * values did not vary much between the different cortical depths (Fig. 4B). Lower $\mathrm{T}_{2}$ * values were found on the apex of the folia of the posterior lobe, while the fissures showed higher values. Patches with high $\mathrm{T}_{2}$ * values were found on the anterior lobe (Fig. 6). Similarly to the $T_{1}$ surfaces, the vermis had a high variability for $\mathrm{T}_{2}$ * values, especially the anterior lobe. Again, the hemispheres showed much lower inter-subject variability. The posterior lobe showed low $\mathrm{T}_{2}$ * values with a "concavity-related" pattern (Fig. 6B, yellow arrow) especially on the posterior region with lower values on the apex. These are likely driven by largescale field gradients that affect the posterior lobe, but not the anterior lobe (see Fig. S2 in the supplementary material for examples of $\mathrm{T}_{2}{ }^{*}$-maps of the cerebellum with an evaluation of the goodness of fit of the nine GRE echos). On the anterior lobe, although different from the $\mathrm{T}_{1}$ pattern, a medio-lateral pattern is also present (Fig. 6A, arrows I, II and III) with higher $\mathrm{T}_{2}$ * values in the medial region to lower values in the lateral regions of the cerebellar hemispheres. This pattern is more pronounced on the outer surface, while being absent on the inner surface in the violin plots (Fig. 5B).

\section{Discussion}

In this study, we performed a cortical surface analysis of $\mathrm{T}_{1}$ and $\mathrm{T}_{2}$ * relaxation times in the human cerebellar cortex in vivo.

The spatial distribution of $\mathrm{qT}_{1}$ evidenced a longitudinal pattern in the parasagittal direction alternating higher and lower $\mathrm{T}_{1}$ values, which was observed at the three different depths from the cerebellar surface. Interestingly, a similar parasagittal pattern had been previously observed in the cerebellum of other species such as the rat (Brochu et al., 1990), cat (Sillitoe et al., 2003) and macaque (Sillitoe et al., 2000), which consisted of alternating stripes of higher and lower specific marker protein levels in Purkinje cells, such as zebrin (Apps and Hawkes, 2009). The stripes observed in these studies showed higher alternating frequencies of zebrin levels, but it is so far unknown what spatial frequency characterizes - if any - the human cerebellum. In alternative or in addition, the observed spatial pattern in $\mathrm{qT}_{1}$ may be due to differences in myelin content (Lutti et al., 2014; Stüber et al., 2014) which might be linked to the zebrin expression. The observed decrease in mean $\mathrm{T}_{1}$ values for the outer to the inner layers parallels a pattern, which has been previously reported in the cerebrum (Sereno et al., 2013; Waehnert et al., 2016) and that has been related to an increase in myelination level in the deeper layers of the cortex (Eickhoff et al., 2005; Walters et al., 2003). These studies also reported a modulation of mean $\mathrm{T}_{1}$ values related to the concavity of the cerebral region (gyri or sulci), which we did not observe within the cerebellar surface as it is most probably dependent on the modelling of the cortical depth (Waehnert et al., 2014).

$\mathrm{T}_{2}$ * surfaces also exhibited longitudinal variations in the parasagittal direction. As observed with $\mathrm{qT}_{1}$, spatial changes in the iron or myelin content (Cohen-Adad, 2014; Cohen-Adad et al., 2012) may be the cause of such changes. Interestingly, in contrast to the $\mathrm{T}_{1}$-maps, the $\mathrm{T}_{2}$ * values did not change as a function of cortical depth, which could be due to the lower sensitivity to myelination of the $\mathrm{T}_{2}{ }^{*}$ contrast compared to the $\mathrm{T}_{1}$ contrast. Additional quantitative susceptibility mapping analysis (Deistung et al., 2011; Langkammer et al., 2012) might help to disentangle the respective contributions of myelin and iron to the contrasts observed here. The difference in $\mathrm{T}_{2}{ }^{*}$ between the vermis and hemispheres is unlikely to be due to segmentation problems as those pointed out in Fig. 2, because the $\mathrm{T}_{2}{ }^{*}$ varies little as a function of cortical depth.

Although high quality $7 \mathrm{~T}$ data were acquired in this first study attempting a quantitative surface analysis of cerebellar cortex in vivo in humans, some limitations remain. These include the lack of spatial resolution to delineate the WM of the smallest embranchments of the arbor vitae, which may have led to some partial volume effects; to fully resolve the arbor vitae in fact, a spatial resolution of approximately $0.1 \mathrm{~mm}$ may be necessary (Marques et al., 2010b), which is currently a challenge in human subjects in vivo. Therefore, a small systematic bias in the layer generation may be present in these data. Also, it would be preferable if surfaces were generated based on the phase contrast of a GRE image to make a separation driven by the different cellular layers, as observed in Marques et al. (2010b), rather than distance to the white matter. However, again, a spatial resolution of $\sim 0.1 \mathrm{~mm}$ isotropic would be required for such a cortical surface analysis and this would imply prohibitive scan times in vivo. Consequently, the observed patterns of the present study revealed medio-lateral variations at the macroscopic level only, similar to the scale on which diffusion tractography is currently performed (Dell'Acqua et al., 2013). While for most of the cerebellar cortical surface quantitative $\mathrm{T}_{1}$ and $\mathrm{T}_{2} *$ could be obtained with high confidence, the consistent low $\mathrm{T}_{2} *$ and $\mathrm{T}_{1}$ values in the most frontal part of the posterior lobe area are likely due to loss of SNR and corresponding poorer $\mathrm{T}_{1}$ and $\mathrm{T}_{2}$ * estimates. The cerebellum remains a challenging brain structure to image, the larger subject induced magnetic inhomogeneity resulted impaired $\mathrm{T}_{2}{ }^{*}$ mapping in the most posterior end of the posterior lobe. The dependence of the cortical folding orientation with the $\mathrm{B}_{0}$ field should also be considered as an additional source contributing to the concavity-related pattern (Cohen-Adad et al., 2012). Moreover, incorporating local magnetic field information in the $\mathrm{T}_{2}$ * estimation might help reducing these large-scale field effects (Sedlacik et al., 2014). In addition, although the cortical geometry is more conserved across subjects in the cerebellum than in the cerebrum, we observed relatively high variability in the vermis, probably due to the underestimation of the cerebellar gray matter in this region during the layer generation or to an inappropriate registration algorithm for this region. Advanced cortical surface registration methods (Robinson et al., 2014; Tardif et al., 2015) may help further refine the $\mathrm{T}_{1}$ and $\mathrm{T}_{2}{ }^{*}$ patterns and reduce the high variability in the vermis. Despite these limitations, the parasagittal pattern in the cerebellar hemispheres and the differences between cortical depths are found in the $\mathrm{T}_{1}$ - and not in the $\mathrm{T}_{2}{ }^{*}$-maps in the same subjects, strongly suggesting that these are indeed caused by myelin concentration differences rather than methodological limitations.

In summary, we observed macroscopic patterns of cerebellar cortical microstructure, which are possibly related to spatial variations in protein, myelin and iron content. Future studies combining 7T quantitative MRI with histological assessments should investigate and confirm the source of global macroscopic patterns we have observed in the human cerebellum cortex.

\section{Conflicts of interest}

K.O., M.J.F. and G.K. work for Siemens AG. The other authors have nothing to disclose.

\section{Acknowledgment}

We would like to gratefully thank Rolf Gruetter for his precious advice on the preliminary results. This work was supported by the Centre d'Imagerie BioMédicale of the UNIL, UNIGE, HUG, CHUV, and EPFL and the Leenaards and Jeantet Foundations and the Swiss National Science Foundation Grants 31003A_153070, 31003A_149983 and PZ00P3_154508.

\section{Appendix A. Supplementary data}

Supplementary data related to this article can be found at https://doi. org/10.1016/j.neuroimage.2018.01.016.

\section{References}

Apps, R., Hawkes, R., 2009. Cerebellar cortical organization: a one-map hypothesis. Nat. Rev. Neurosci. 10, 670-681. https://doi.org/10.1038/nrn2698.

Armstrong, D.M., Schild, R.F., 1970. A quantitative study of the Purkinje cells in the cerebellum of the albino rat. J. Comp. Neurol. 449-456. 
Avants, B.B., Epstein, C.L., Grossman, M., Gee, J.C., 2008. Symmetric diffeomorphic image registration with cross-correlation: evaluating automated labeling of elderly and neurodegenerative brain. Med. Image Anal. 12, 26-41. https://doi.org/10.1016/ j.media.2007.06.004.

Bazin, P.L., Weiss, M., Dinse, J., Schäfer, A., Trampel, R., Turner, R., 2014. A computational framework for ultra-high resolution cortical segmentation at 7 Tesla. Neuroimage 93, 201-209. https://doi.org/10.1016/ j.neuroimage.2013.03.077.

Bazin, P.L., Weiss, M., Dinse, J., Schäfer, A., Trampel, R., Turner, R., 2013. A computational framework for ultra-high resolution cortical segmentation at 7 Tesla. Neuroimage 93, 201-209. https://doi.org/10.1016/ j.neuroimage. 2013.03.077.

Bogovic, J. a., Prince, J.L., Bazin, P.-L., 2013. A multiple object geometric deformable model for image segmentation. Comput. Vis. Image Understand. 117, 145-157. https://doi.org/10.1016/j.cviu.2012.10.006.

Boillat, Y., O'Brien, K., de Oliveira, M.J.F., Bonnier, G., Krueger, G., van der Zwaag, W., Granziera, C., 2016. Lobule-wise quantitative T1 and T2* analysis of cerebellar grey matter in multiple sclerosis patients at 7T MRI. Proc. Intl. Soc. Mag. Reson. Med 24, 5110.

Bonnier, G., Roche, A., Romascano, D., Simioni, S., Meskaldji, D., Rotzinger, D., Lin, Y.-C., Menegaz, G., Schluep, M., Du Pasquier, R., Sumpf, T.J., Frahm, J., Thiran, J.-P., Krueger, G., Granziera, C., 2014. Advanced MRI unravels the nature of tissue alterations in early multiple sclerosis. Ann. Clin. Transl. Neurol 1, 423-432. https:// doi.org/10.1002/acn3.68.

Bonnier, G., Roche, A., Romascano, D., Simioni, S., Meskaldji, D.E., Rotzinger, D., Lin, Y., Menegaz, G., Schluep, M., Du Pasquier, R., Sumpf, T.J., Frahm, J., Thiran, J., Krueger, G., Granziera, C., 2015. Multicontrast MRI quantification of focal inflammation and degeneration in multiple sclerosis. https://doi.org/10.1155/2015/ 569123.

Brochu, G., Maler, L., Hawkes, R., 1990. Zebrin II: a polypeptide antigen expressed selectively by Purkinje cells reveals compartments in rat and fish cerebellum. J. Comp. Neurol. 291, 538-552. https://doi.org/10.1002/cne.902910405.

Cajal, S.R., 1911. Histologie du système nerveux de l'homme et des vertébrés, vol. 2. Paris Maloine, pp. 891-942. https://doi.org/10.5962/bhl.title.48637.

Carass, A., Cuzzocreo, J., Wheeler, M.B., Bazin, P.L., Resnick, S.M., Prince, J.L., 2011 Simple paradigm for extra-cerebral tissue removal: algorithm and analysis. Neuroimage 56, 1982-1992. https://doi.org/10.1016/j.neuroimage.2011.03.045.

Cerminara, N.L., Lang, E.J., Sillitoe, R.V., Apps, R., 2015. Redefining the cerebellar cortex as an assembly of non-uniform Purkinje cell microcircuits. Nat. Rev. Neurosci. 16, 79-93. https://doi.org/10.1038/nrn3886.

Cohen-Adad, J., 2014. What can we learn from T2* maps of the cortex? Neuroimage 93 , 189-200. https://doi.org/10.1016/j.neuroimage.2013.01.023.

Cohen-Adad, J., Polimeni, J.R., Helmer, K.G., Benner, T., McNab, J. a., Wald, L.L., Rosen, B.R., Mainero, C., 2012. T 2* mapping and B 0 orientation-dependence at $7 \mathrm{~T}$ reveal cyto- and myeloarchitecture organization of the human cortex. Neuroimage 60, 1006-1014. https://doi.org/10.1016/j.neuroimage.2012.01.053.

Deistung, A., Schäfer, A., Schweser, F., Biedermann, U., Turner, R., Reichenbach, J.R., 2011. NeuroImage toward in vivo histology: a comparison of quantitative susceptibility mapping ( QSM ) * -imaging at ultra-high magnetic fi eld strength with magnitude-, phase-, and R 2. Neuroimage 65, 299-314. https://doi.org/10.1016/ j.neuroimage.2012.09.055

Dell'Acqua, F., Bodi, I., Slater, D., Catani, M., Modo, M., 2013. MR diffusion histology and micro-tractography reveal mesoscale features of the human cerebellum. Cerebellum 12, 923-931. https://doi.org/10.1007/s12311-013-0503-x.

Dinse, J., Härtwich, N., Waehnert, M.D., Tardif, C.L., Schäfer, a., Geyer, S., Preim, B. Turner, R., Bazin, P.L., 2015. A cytoarchitecture-driven myelin model reveals areaspecific signatures in human primary and secondary areas using ultra-high resolution in-vivo brain MRI. Neuroimage 114, 71-87. https://doi.org/10.1016/ j.neuroimage.2015.04.023.

Duyn, J.H., 2012. The future of ultra-high field MRI and fMRI for study of the human brain. Neuroimage 62, 1241-1248. https://doi.org/10.1016/ j.neuroimage.2011.10.065.

Eggenschwiler, F., Kober, T., Magill, A.W., Gruetter, R., Marques, J.P., 2012. SA2RAGE: a new sequence for fast B1+ -mapping. Magn. Reson. Med. 67, 1609-1619. https:// doi.org/10.1002/mrm.23145.

Eickhoff, S., Walters, N.B., Schleicher, A., Kril, J., Egan, G.F., Zilles, K., Watson, J.D.G., Amunts, K., 2005. High-resolution MRI reflects myeloarchitecture and cytoarchitecture of human cerebral cortex. Hum. Brain Mapp. 24, 206-215. https:// doi.org/10.1002/hbm.20082.

Fartaria, M.J., O’Brien, K., Şorega, A., Bonnier, G., Roche, A., Falkovskiy, P., Krueger, G., Kober, T., Bach Cuadra, M., Granziera, C., 2016. An ultra-high field study of cerebellar pathology in early relapsing-remitting multiple sclerosis using MP2RAGE Invest. Radiol. 0, 1. https://doi.org/10.1097/RLI.0000000000000338.

Fujita, H., Oh-Nishi, A., Obayashi, S., Sugihara, I., 2010. Organization of the marmoset cerebellum in three-dimensional space: lobulation, aldolase c compartmentalization and axonal projection. J. Comp. Neurol. 518, 1764-1791. https://doi.org/10.1002/ cne.22301.

Fujita, H., Sugihara, I., 2013. Branching patterns of olivocerebellar axons in relation to the compartmental organization of the cerebellum. Front. Neural Circ. 7, 3. https:// doi.org/10.3389/fncir.2013.00003.

Fukunaga, M., Li, T.-Q., van Gelderen, P., de Zwart, J. a., Shmueli, K., Yao, B., Lee, J., Maric, D., Aronova, M. a., Zhang, G., Leapman, R.D., Schenck, J.F., Merkle, H., Duyn, J.H., 2010. Layer-specific variation of iron content in cerebral cortex as a source of MRI contrast. Proc. Natl. Acad. Sci. 107, 3834-3839. https://doi.org/ 10.1073/pnas.0911177107.
Groenewegen, H.J., Voogd, J., 1977. The parasagittal zonation within the olivocerebellar projection. I. Climbing fiber distribution in the vermis of cat cerebellum. J. Comp. Neurol. 174, 417-488. https://doi.org/10.1002/cne.901740304.

Han, X., Pham, D.L., Tosun, D., Rettmann, M.E., Xu, C., Prince, J.L., 2004. CRUISE: cortical reconstruction using implicit surface evolution. Neuroimage 23, 997-1012. https://doi.org/10.1016/j.neuroimage.2004.06.043.

Helms, G., 2013. Tissue Properties from Quantitative MRI, Brain Mapping: an Encyclopedic Reference. Elsevier Inc. https://doi.org/10.1016/B978-0-12-3970251.00297-9.

Hwang, D., Kim, D.H., Du, Y.P., 2010. In vivo multi-slice mapping of myelin water content using T2* decay. Neuroimage 52, 198-204. https://doi.org/10.1016/ j.neuroimage. 2010.04.023.

Jenkinson, M., Smith, S., 2001. A global optimisation method for robust affine registration of brain images. Med. Image Anal. 5, 143-156. https://doi.org/10.1016/ S1361-8415(01)00036-6.

Klein, S., Staring, M., Murphy, K., Viergever, M. a., Pluim, J., 2010. Elastix : a Toolbox for Intensity-Based Medical Image Registration. IEEE Trans. Med. Imag. 29, 196-205. https://doi.org/10.1109/TMI.2009.2035616.

Kutzelnigg, A., Faber-Rod, J.C., Bauer, J., Lucchinetti, C.F., Sorensen, P.S., Laursen, H., Stadelmann, C., Brück, W., Rauschka, H., Schmidbauer, M., Lassmann, H., 2007. Widespread demyelination in the cerebellar cortex in multiple sclerosis. Brain Pathol. 17, 38-44. https://doi.org/10.1111/j.1750-3639.2006.00041.x.

Lange, W., 1982. Regional differences in the cytoarchitecture of the cerebellar cortex. In: Palay, S.L., Chan-Palay (Eds.), The Cerebellum- New Vistas. Springer-Verlag, Berlin, pp. 93-105.

Langkammer, C., Schweser, F., Krebs, N., Deistung, A., Goessler, W., Scheurer, E., Sommer, K., Reishofer, G., Yen, K., Fazekas, F., Ropele, S., Reichenbach, J.R., 2012. Quantitative susceptibility mapping (QSM) as a means to measure brain iron? A post mortem validation study. Neuroimage 62, 1593-1599. https://doi.org/10.1016/ j.neuroimage.2012.05.049.

Lutti, A., Dick, F., Sereno, M.I., Weiskopf, N., 2014. Using high-resolution quantitative mapping of R1 as an index of cortical myelination. Neuroimage 93, 176-188. https:// doi.org/10.1016/j.neuroimage.2013.06.005.

Mainero, C., Louapre, C., Govindarajan, S.T., Gianni, C., Scott Nielsen, a., Cohen-Adad, J., Sloane, J., Kinkel, R.P., 2015. A gradient in cortical pathology in multiple sclerosis by in vivo quantitative $7 \mathrm{~T}$ imaging. Brain 138, 932-945. https://doi.org/10.1093/ brain/awv011.

Marques, J.P., Gruetter, R., 2013. New developments and applications of the MP2RAGE sequence-focusing the contrast and high spatial resolution R1 mapping. PLoS One 8, e69294. https://doi.org/10.1371/journal.pone.0069294.

Marques, J.P., Kober, T., Krueger, G., van der Zwaag, W., Van de Moortele, P.-F., Gruetter, R., 2010a. MP2RAGE, a self bias-field corrected sequence for improved segmentation and T1-mapping at high field. Neuroimage 49, 1271-1281. https:// doi.org/10.1016/j.neuroimage.2009.10.002.

Marques, J.P., van der Zwaag, W., Granziera, C., Krueger, G., Gruetter, R., 2010b. Cerebellar cortical layers: in vivo visualization with structural high-field-strength MR imaging. Radiology 254, 942-948. https://doi.org/10.1148/radiol.09091136.

Marzban, H., Hawkes, R., 2011. On the architecture of the posterior zone of the cerebellum. Cerebellum 10, 422-434. https://doi.org/10.1007/s12311-010-0208-3.

Meabon, J.S., Huber, B.R., Cross, D.J., Richards, T.L., Minoshima, S., Pagulayan, K.F., Li, G., Meeker, K.D., Kraemer, B.C., Petrie, E.C., Raskind, M. a., Peskind, E.R., Cook, D.G., 2016. Repetitive blast exposure in mice and combat veterans causes persistent cerebellar dysfunction. Sci. Transl. Med. 8, 321ra6 https://doi.org/ 10.1126/scitranslmed.aaa9585.

Müller, U., Heinsen, H., 1983. Regional differences in the ultrastructure of Purkinje cells of the rat. Cell Tissue Res. 235, 91-98. https://doi.org/10.1007/BF00213728.

Pham, D.L., 2001. Robust fuzzy segmentation of magnetic resonance images. IEEE Symp. Comput. Med. Syst 127-131.

Piao, Y.S., Hayashi, S., Wakabayashi, K., Kakita, A., Aida, I., Yamada, M., Takahashi, H., 2002. Cerebellar cortical tau pathology in progressive supranuclear palsy and corticobasal degeneration. Acta Neuropathol. 103, 469-474. https://doi.org/ 10.1007/s00401-001-0488-2.

Pijpers, A., Apps, R., Pardoe, J., Voogd, J., Ruigrok, T.J.H., 2006. Precise spatial relationships between mossy fibers and climbing fibers in rat cerebellar cortical zones. J. Neurosci. 26, 12067-12080. https://doi.org/10.1523/JNEUROSCI.290506.2006.

Pijpers, A., Voogd, J., Ruigrok, T.J.H., 2005. Topography of olivo-cortico-nuclear modules in the intermediate cerebellum of the rat. J. Comp. Neurol. 492, 193-213. https:// doi.org/10.1002/cne.20707.

Robinson, E.C., Jbabdi, S., Glasser, M.F., Andersson, J., Burgess, G.C., Harms, M.P., Smith, S.M., Van Essen, D.C., Jenkinson, M., 2014. MSM: a new flexible framework for multimodal surface matching. Neuroimage 100, 414-426. https://doi.org/ 10.1016/j.neuroimage.2014.05.069.

Ruigrok, T.J.H., 2011. Ins and outs of cerebellar modules. Cerebellum 10, 464-474. https://doi.org/10.1007/s12311-010-0164-y.

Schniepp, R., Möhwald, K., Wuehr, M., 2017. Gait ataxia in humans: vestibular and cerebellar control of dynamic stability. J. Neurol. https://doi.org/10.1007/s00415 017-8482-3.

Sedlacik, J., Boelmans, K., Löbel, U., Holst, B., Siemonsen, S., Fiehler, J., 2014. Reversible, irreversible and effective transverse relaxation rates in normal aging brain at 3T. Neuroimage 84, 1032-1041. https://doi.org/10.1016/ j.neuroimage.2013.08.051.

Sereno, M.I., Lutti, A., Weiskopf, N., Dick, F., 2013. Mapping the human cortical surface by combining quantitative T1 with retinotopy. Cerebr. Cortex 23, 2261-2268. https://doi.org/10.1093/cercor/bhs213. 
Sillitoe, R.V., Hulliger, M., Dyck, R., Hawkes, R., 2003. Antigenic compartmentation of the cat cerebellar cortex, 977, 1-15.

Sillitoe, R.V., Malz, C.R., Rockland, K., Hawkes, R., 2000. Antigenic Compartmentation of the Primate and Tree Shrew Cerebellum: a Common Topography of Zebrin II in Macaca mulatta and Tupaia Belangeri, pp. 257-269.

Stüber, C., Morawski, M., Schäfer, A., Labadie, C., Wähnert, M., Leuze, C., Streicher, M. Barapatre, N., Reimann, K., Geyer, S., Spemann, D., Turner, R., 2014. Myelin and iron concentration in the human brain: a quantitative study of MRI contrast. Neuroimage 93, 95-106. https://doi.org/10.1016/j.neuroimage.2014.02.026.

Sugihara, I., 2004. Molecular, topographic, and functional organization of the cerebellar cortex: a study with combined aldolase $C$ and olivocerebellar labeling. J. Neurosci. 24, 8771-8785. https://doi.org/10.1523/JNEUROSCI.1961-04.2004.

Tardif, C.L., Schäfer, A., Waehnert, M., Dinse, J., Turner, R., Bazin, P.L., 2015. Multicontrast multi-scale surface registration for improved alignment of cortical areas. Neuroimage 111, 107-122. https://doi.org/10.1016/j.neuroimage.2015.02.005.

Teeuwisse, W.M., Brink, W.M., Webb, A.G., 2012. Quantitative assessment of the effects of high-permittivity pads in 7 Tesla MRI of the brain. Magn. Reson. Med. 67, 1285-1293. https://doi.org/10.1002/mrm.23108.

Tsutsumi, S., Yamazaki, M., Miyazaki, T., Watanabe, M., Sakimura, K., Kano, M., Kitamura, K., 2015. Structure-function relationships between aldolase C/Zebrin II expression and complex spike synchrony in the cerebellum. J. Neurosci. 35, 843-852. https://doi.org/10.1523/JNEUROSCI.2170-14.2015.

Van der Weerd, L., Vergeldt, F.J., Adrie de Jager, P., Van As, H., 2000. Evaluation of algorithms for analysis of NMR relaxation decay curves. Magn. Reson. Imaging 18, 1151-1157. https://doi.org/10.1016/S0730-725X(00)00200-9. van der Zwaag, W., Schäfer, A., Marques, J.P., Turner, R., Trampel, R., 2015. Recent applications of UHF-MRI in the study of human brain function and structure: a review. NMR Biomed. https://doi.org/10.1002/nbm.3275.

Voogd, J., 2011. Cerebellar zones: a personal history. Cerebellum 10, 334-350. https:// doi.org/10.1007/s12311-010-0221-6.

Waehnert, M.D., Dinse, J., Schäfer, A., Geyer, S., Bazin, P.L., Turner, R., Tardif, C.L., 2016. A subject-specific framework for in vivo myeloarchitectonic analysis using high resolution quantitative MRI. Neuroimage 125, 94-107. https://doi.org/10.1016/ j.neuroimage.2015.10.001.

Waehnert, M.D., Dinse, J., Weiss, M., Streicher, M.N., Waehnert, P., Geyer, S., Turner, R., Bazin, P.L., 2014. Anatomically motivated modeling of cortical laminae. Neuroimage 93, 210-220. https://doi.org/10.1016/j.neuroimage.2013.03.078.

Walters, N.B., Egan, G.F., Kril, J.J., Kean, M., Waley, P., Jenkinson, M., Watson, J.D.G., 2003. In vivo identification of human cortical areas using high-resolution MRI: an approach to cerebral structure-function correlation. Proc. Natl. Acad. Sci. U. S. A 100, 2981-2986. https://doi.org/10.1073/pnas.0437896100.

Witter, L., De Zeeuw, C.I., 2015. Regional functionality of the cerebellum. Curr. Opin. Neurobiol. 33, 150-155. https://doi.org/10.1016/j.conb.2015.03.017.

Wyatt, K.D., Tanapat, P., Wang, S.S.H., 2005. Speed limits in the cerebellum: constraints from myelinated and unmyelinated parallel fibers. Eur. J. Neurosci. 21, 2285-2290. https://doi.org/10.1111/j.1460-9568.2005.04053.x.

Yushkevich, P. a., Piven, J., Hazlett, H.C., Smith, R.G., Ho, S., Gee, J.C., Gerig, G., 2006. User-guided 3D active contour segmentation of anatomical structures: significantly improved efficiency and reliability. Neuroimage 31, 1116-1128. https://doi.org/ 10.1016/j.neuroimage.2006.01.015. 